\title{
Short communication: Limit feeding affects behavior patterns and feeding motivation of dairy heifers
}

\author{
A. M. Greter, ${ }^{*}$ E. K. Miller-Cushon,† B. W. McBride,‡ T. M. Widowski,‡ T. F. Duffield,§ and T. J. DeVries* \\ *Department of Animal and Poultry Science, University of Guelph, Kemptville Campus, Kemptville, ON, K0G 1J0, Canada \\ †Department of Animal Sciences, University of Florida, Gainesville 32611 \\ ‡Department of Animal and Poultry Science, University of Guelph, Guelph, ON, N1G 2W1, Canada \\ §Department of Population Medicine, Ontario Veterinary College, University of Guelph, Guelph, ON, N1G 2W1, Canada
}

\section{ABSTRACT}

The study objective was to assess the effects of limit feeding dairy heifers on behavior patterns and feeding motivation. Ten Holstein heifers $(291.6 \pm 39.2$ d of age, weighing $324.2 \pm 61.2 \mathrm{~kg}$; mean $\pm \mathrm{SD}$ ) were exposed to each of 2 dietary treatments, in a random order, over 2 successive $26-\mathrm{d}$ treatment periods (14-d adaptation period and a 12-d data collection period) using a crossover design: (1) a high-forage total mixed ration (TMR), provided ad libitum (CON) and (2) a low-forage TMR, limit-fed at $2.05 \%$ body weight (LF). Heifers were fed daily at $1100 \mathrm{~h}$ and motivation to access a low-nutritive feedstuff (straw) was assessed using a push-door apparatus at 2 time points: $3 \mathrm{~h}$ after feed delivery (1400 h) and $21 \mathrm{~h}$ after feed delivery $(0800 \mathrm{~h})$. The amount of weight pushed, weight pushed as percentage of body weight, and latency to access the push door were recorded on 3 different days for each heifer at each time point on each treatment. When fed CON, heifers had greater dry matter intake $(12.9$ vs. $7.2 \mathrm{~kg} / \mathrm{d})$, greater feeding time ( 209.3 vs. $82.4 \mathrm{~min} / \mathrm{d}$ ), greater ruminating time (452.2 vs. $318.3 \mathrm{~min} / \mathrm{d}$ ), and slower rates of intake (0.06 vs. $0.09 \mathrm{~kg}$ of dry matter $/ \mathrm{min}$ ) than when fed LF. Heifers fed LF pushed more weight as a percentage of body weight at $3 \mathrm{~h}(4.5$ vs. $1.9 \%)$ and $21 \mathrm{~h}$ (9.3 vs. $2.8 \%$ ) after feed delivery. At both 3 and $21 \mathrm{~h}$ after feed delivery, latency to access the door was shorter for the LF heifers compared with the CON heifers (65 vs. 145 $\mathrm{s})$. These results indicate that, in addition to decreasing feeding time, limit feeding increases motivation of heifers to access a low-nutritive feedstuff, possibly due to lack of satiety resulting from lack of physical fill or insufficient time spent foraging.

Key words: dairy heifer, feeding behavior, limit feeding, motivation

Received September 20, 2014.

Accepted November 5, 2014.

${ }^{1}$ Corresponding author: tdevries@uoguelph.ca

\section{Short Communication}

Limit feeding, by providing a nutrient-dense ration at a predetermined amount, is a feeding strategy for dairy heifers used within the dairy industry. This feeding strategy is relevant from both an environmental and economic perspective, because it supports targeted ADG while reducing fecal nitrogen excretion and feed costs, due to an increase in feed efficiency (Hoffman et al., 2007; Lascano et al., 2009). However, limit feeding may raise welfare concerns due to its effects on behavior: reduced feeding and lying time, and increased time spent standing without eating (Hoffman et al., 2007; Kitts et al., 2011; Greter et al., 2011). Further, limit-fed dairy cattle vocalize more frequently (Hoffman et al., 2007) and perform more oral stereotypies (Redbo et al., 1996). Given that cattle engage in foraging behavior for 4 to $9 \mathrm{~h} / \mathrm{d}$ in natural conditions (Kilgour, 2012), the changes in behavior associated with limit feeding may be attributed to lack of satiety resulting from either a lack of gut fill or insufficient foraging time.

Recent research suggests that limit-fed heifers (fed at $\sim 2 \%$ of $\mathrm{BW}$ ) consume quantities of a low-nutritive feedstuff when it is offered alongside their TMR, resulting in greater feeding and rumination time without affecting targeted ADG (Greter et al., 2011; Kitts et al., 2011). Lindström and Redbo (2000) demonstrated that lactating dairy cows spend time manipulating feed even when their rumens are filled artificially, suggesting that cattle may have a behavioral need to perform foraging behavior even when metabolically satiated. Assessing the motivation of limit-fed dairy heifers to obtain access to a foraging substrate would clarify whether the opportunity to forage is important to the heifer and, consequently, whether limit feeding heifers and restricting foraging time could negatively affect their welfare.

Operant tests are an effective means for measuring feeding motivation (D'Eath et al., 2009) and providing insight into the subjective states associated with feeding motivation (Kirkden and Pajor, 2006). Jackson et al. (1999) assessed feeding motivation of sheep by increasing the amount of weight on a push door to obtain 
a feed reward and found that sheep were more willing to push heavier weights following a period of feed deprivation of $6 \mathrm{~h}$. Similarly, latency to open a weighted push door decreases as the duration of food deprivation increases in hens (Olsson and Keeling, 2002). These results indicate that a weighted push door may be an effective means of assessing feeding motivation associated with limit feeding.

The objective of this study was to assess how feeding behavior patterns and feeding motivation of dairy heifers are influenced by limit feeding, in comparison with conventional ad libitum feeding of a high-forage diet. The hypothesis was that heifers would work harder for access to a low-nutritive feedstuff when limit-fed a low-forage diet, compared with when provided a highforage diet ad libitum. Further, it was hypothesized that motivation to obtain access to the low-nutritive feedstuff would increase with time since feed delivery, especially when limit-fed.

Ten Holstein dairy heifers were used in this study. Heifers were $291.6 \pm 39.2$ (mean $\pm \mathrm{SD}$ ) d of age and weighed $324.2 \pm 61.2 \mathrm{~kg}$ at the beginning of the study and weighed $378.7 \pm 63.0 \mathrm{~kg}$ at the end of the study. Heifers were housed in a tie-stall barn at the University of Guelph, Kemptville Campus (Kemptville, Ontario, Canada) and were managed according to the guidelines set by the Canadian Council on Animal Care (2009). Use of heifers was approved by the University of Guelph's Animal Care Committee (AUP\#09R022). Each heifer was individually housed in a tie stall (203 $\times 124.5 \times 91 \mathrm{~cm}$; length $\times$ width $\times$ height), bedded with wood shavings, where she had ad libitum access to water (via her own water bowl) and access to feed via her own feed bunk (individual feed bunks were separated with dividers). Heifers were given a 2 -h exercise period (0900 to $1100 \mathrm{~h}$ ) each day in an outdoor dry lot pen. Heifers were given ad libitum access to trace mineral salt blocks while in the exercise yard (Windsor TM Stock Salt, The Canadian Salt Company Limited, Pointe-Claire, Quebec, Canada).

The number of animals required per treatment was determined through power analysis (Morris, 1999) for primary response variables, including feeding behavior measures. Estimates of variation for these variables were based on previously reported values (Greter et al., 2008; Kitts et al., 2011). Heifers were fed (Table 1) either (1) a low-forage TMR fed at a restricted level of $2.05 \%$ BW ( $\mathbf{L F})$ or (2) a high-forage control TMR ad libitum $(\mathbf{C O N})$, that were formulated to meet the nutrient requirements for a nonbred Holstein heifer growing at $0.9 \mathrm{~kg} / \mathrm{d}(\mathrm{NRC}, 2001)$.

The limit feeding protocol used in this study was representative of on-farm recommendations (Zanton and Heinrichs, 2008) and in line with feeding levels used in other studies providing low-forage diets (e.g., $2.02 \%$ BW, Kitts et al., 2011; and 1.93\% BW, Lascano et al., 2009). In contrast, the predicted ad libitum intake of the high-forage ration was approximately $2.29 \%$ of BW (NRC, 2001). Heifers had been fed a low-forage TMR for $4 \mathrm{wk}$ before the start of this experiment. Heifers were exposed to each of the 2 dietary treatments, in a random order, over 2 successive 26 - $\mathrm{d}$ treatment periods using a crossover design. These periods included a 14-d adaptation period, and a 12-d data collection period. When heifers were switched from the CON ration to the LF ration, the amount of haylage was decreased by $5 \%$ each day over the first $7 \mathrm{~d}$ of the adaptation period, to facilitate gradual adaptation of rumen microbes to the low-forage ration.

Individual intakes were recorded daily throughout the study by weighing the amount of feed offered and amount of feed refused (if any) using a calibrated floor scale precise to the nearest $0.1 \mathrm{~kg}$ (model 31-0851T17430, Toledo Scale Company of Canada Ltd., Windsor, ON, Canada). These data were used to calculate daily DMI $(\mathrm{kg} / \mathrm{d})$. Heifers were weighed on the same 2 consecutive days each week, and these weekly weights

Table 1. Ingredient, chemical composition, and calculated nutrients $($ mean $\pm \mathrm{SD})$ of the rations

\begin{tabular}{|c|c|c|}
\hline Composition & $\begin{array}{c}\text { Limit-fed } \\
\text { TMR }\end{array}$ & $\begin{array}{c}\text { Control } \\
\text { TMR }\end{array}$ \\
\hline \multicolumn{3}{|l|}{ Ingredient $(\%$ of DM) } \\
\hline Corn silage 1 & 20.0 & 20.0 \\
\hline Grass/alfalfa haylage ${ }^{2}$ & 20.0 & 50.4 \\
\hline High moisture corn & 43.0 & 22.1 \\
\hline Protein supplement $^{3}$ & 17.0 & 7.5 \\
\hline \multicolumn{3}{|l|}{ Chemical composition $^{4}$} \\
\hline $\mathrm{DM}(\%)$ & $59.3 \pm 2.7$ & $49.1 \pm 2.8$ \\
\hline $\mathrm{OM}(\%$ of $\mathrm{DM})$ & $92.6 \pm 0.3$ & $92.1 \pm 0.8$ \\
\hline $\mathrm{CP}(\%$ of $\mathrm{DM})$ & $16.9 \pm 0.6$ & $16.8 \pm 0.3$ \\
\hline $\mathrm{ADF}(\%$ of $\mathrm{DM})$ & $12.6 \pm 1.3$ & $18.1 \pm 0.8$ \\
\hline NDF ( $\%$ of DM) & $22.4 \pm 1.9$ & $29.9 \pm 2.3$ \\
\hline NFC (\% of DM) & $49.6 \pm 1.7$ & $42.2 \pm 3.0$ \\
\hline \multicolumn{3}{|l|}{ Calculated nutrient } \\
\hline $\mathrm{TDN}^{5}(\%$ of $\mathrm{DM})$ & $78.0 \pm 0.5$ & $73.3 \pm 0.5$ \\
\hline ME (Mcal/kg) & $2.82 \pm 0.02$ & $2.65 \pm 0.02$ \\
\hline $\mathrm{NE}_{\mathrm{G}}(\mathrm{Mcal} / \mathrm{kg})$ & $1.24 \pm 0.01$ & $1.11 \pm 0.01$ \\
\hline $\mathrm{NE}_{\mathrm{M}}(\mathrm{Mcal} / \mathrm{kg})$ & $1.88 \pm 0.01$ & $1.73 \pm 0.02$ \\
\hline
\end{tabular}

${ }^{1}$ Corn silage composition: $41.9 \pm 2.9 \% \mathrm{DM}, 8.7 \pm 0.0 \% \mathrm{CP}, 31.6 \pm$ $1.3 \% \mathrm{NDF}, 53.5 \pm 1.3 \% \mathrm{NFC}$.

${ }^{2}$ Haylage composition: $36.4 \pm 4.9 \%$ DM, $18.6 \pm 2.4 \%$ CP, $49.0 \pm 5.0 \%$ $\mathrm{NDF}, 19.5 \pm 3.9 \% \mathrm{NFC}$.

${ }^{3}$ Supplied by Dundas Feed and Seed (Winchester, ON, Canada), containing (on as-is basis): $25.6 \%$ corn gluten meal, $24.4 \%$ Tri-Pro Gold (Tri-County Protein Corp., Winchester, ON, Canada), $24.4 \%$ soybean meal, $10.0 \%$ canola meal, $4.8 \%$ ground limestone, $4.5 \%$ trace mineral/vitamin premix, $4.4 \%$ sodium bicarbonate, and $1.9 \%$ cobaltizediodized salt.

${ }^{4}$ Values were obtained from chemical analysis of TMR samples. NFC $=100-(\% \mathrm{CP}+\% \mathrm{NDF}+\%$ fat $+\%$ ash $)$.

${ }^{5}$ Total digestible nutrients (calculated from ingredients). 
were averaged for each heifer and used to calculate BW to determine feed amounts.

Feeding motivation was assessed using a push-door apparatus. The push door was designed to fit into the feed manger of the tie stall. The skeleton door frame was the same width as the tie stall and was situated in front of the tie stall at all times during the experiment, not obstructing the animal's ability to lie down, get up, or consume feed. When set in place on the door frame, the door completely blocked the feed bunk when closed and heifers were required to push on it with their head, such that the door pivoted outwards, to reach feed. The door was constructed of horizontal steel bars spaced at $15 \mathrm{~cm}$, such that heifers could easily see feed available on the other side of the door, but could not reach through or around the door. A metal post was fixed perpendicularly to the door, on the side opposite the heifer, such that weights could be added to increase the weight of the door. The door, without added weights, weighed $8 \mathrm{~kg}$ and measured $1.2 \times 1.3 \mathrm{~m}$ (width $\times$ height).

Daily training sessions were conducted during the $3 \mathrm{~d}$ before the data collection period. During these sessions, the door was placed in position such that heifers were required to push the door for access to their normal ration. Training sessions terminated either when the heifer pushed the door and accessed feed once, or after 5 min had elapsed. By the final training day, all heifers pushed the door for access to their feed before the training session terminated, indicating that they had learned how to operate the door.

Over the $12 \mathrm{~d}$ of the data collection period, heifers were tested for feeding motivation using the push-door apparatus at 2 time points: $1400 \mathrm{~h}(3 \mathrm{~h}$ after feed delivery, and immediately following consumption of all feed by LF heifers) and $0800 \mathrm{~h}$ ( $21 \mathrm{~h}$ after feed delivery). Each heifer was tested at both time points on 3 separate testing days on both treatments. Heifers were given at least $24 \mathrm{~h}$ between subsequent tests. Time of the first test $(1400$ or $0800 \mathrm{~h})$ was randomly allocated on the first day of testing, and time of test was alternated between consecutive tests. Immediately before the test, feed was temporarily removed (if any remained). The push door was placed in front of the heifer and oat straw was offered in $0.5-\mathrm{kg}$ amounts behind the push door. Each time a heifer pushed the door to access the straw, a $2.3-\mathrm{kg}$ weight was added to the door. Additional parcels of straw were added as needed. The test concluded when either (1) 10 min elapsed without the heifer pushing the door or (2) the heifer contacted or attempted to push the door but did not successfully access straw. During each test, data recorded were the latency to first push the door, number of times the door was pushed, and maximum amount of weight pushed.
For analysis, weight pushed as a percentage of BW was also calculated.

During the last $7 \mathrm{~d}$ of each recording period, feeding behavior was monitored continuously using time-lapse video. Heifers were recorded using 4 video cameras (Panasonic WV-BP330, Osaka, Japan), a time-lapse video cassette recorder (Panasonic AG-6740) and a video multiplexer (Panasonic WJ-FS 616). Each camera was positioned in front of the tie stalls $(2.08 \mathrm{~m}$ off the floor and $0.53 \mathrm{~m}$ from the tie rail) such that 2 or 3 heifers could be recorded by each camera. The amount of time spent feeding during the 7 -d recording period was scored for individual heifers using instantaneous scans at 5 -min intervals (scanning frequency $\leq 10 \mathrm{~min}$ was validated by Kitts et al., 2011). For each scan, feeding was defined as being when a heifer had her head completely past the feed curb and over the feed. Time spent ruminating was assessed on $\mathrm{d} 2,4$, and 6 of each 7-d video recording period by watching video continuously and recording the presence of rumination (defined as repetitive jaw movement evident while not feeding) at 5-min intervals. Data obtained from instantaneous scans were used to estimate total daily feeding and ruminating time (number of positive scans $\times$ scanning interval of $5 \mathrm{~min}$ ). Daily average rate of intake was calculated for individual heifers as intake divided by feeding time. To identify changes in diurnal feeding patterns between treatments, these data were also used to calculate hourly averages for time spent feeding and ruminating over each 24 -h period.

Feed samples were taken of the TMR for DM and chemical analysis during the last $12 \mathrm{~d}$ of each treatment period. Samples of the dietary components were also taken (in duplicate) for DM analysis and chemical analysis during each of these recording periods. Samples taken for DM and chemical analysis were oven-dried at $55^{\circ} \mathrm{C}$ for $48 \mathrm{~h}$ and then ground to pass through a $1-\mathrm{mm}$ screen (Wiley Mill, Arthur H. Thomas Co., Philadelphia, PA). These samples were then sent to Cumberland Valley Analytical Services Inc. (Maugansville, $\mathrm{MD})$ for analysis of $\mathrm{DM}\left(135^{\circ} \mathrm{C}\right.$; AOAC International, 2000: method 930.15), ADF (AOAC International, 2000: 973.18), NDF with heat-stable $\alpha$-amylase and sodium sulfite (Van Soest et al., 1991), and CP (N × 6.25; AOAC International, 2000: method 990.03; Leco FP-528 Nitrogen Analyzer, Leco, St. Joseph, MI).

For analyses of intake and feeding behavior measures, data were summarized by heifer and period. To test for the effect of treatment, data were analyzed using the MIXED procedure of SAS (SAS Institute Inc., 2009). The model included the fixed effect of period, treatment, and order of exposure to treatment, the random effect of heifer within order, and the residual error. To test for the effect of treatment on diurnal feeding patterns, 
the data were analyzed using the MIXED procedure of SAS (SAS Institute Inc., 2009) treating hour as a repeated measure. The model included the fixed effects of period, treatment, hour, and treatment $\times$ hour interaction and the random effect of heifer. The covariance structure was compound symmetry, according to the best-fit Schwarz's Bayesian information criterion.

Preliminary analysis was performed on data obtained in motivational tests to assess whether response (weight pushed and latency to push) was consistent across consecutive tests at each time point. This was done to verify that response was not influenced by repeated exposure to the push door, which may have suggested that heifers were not properly trained to use the door before the testing period. This was assessed separately by test time (1400 or $0800 \mathrm{~h}$ ) using the MIXED procedure of SAS (SAS Institute Inc., 2009) treating test number (1, 2 , or 3 ) as a repeated measure in a model that included the fixed effects of treatment, test number, test number $\times$ treatment interaction, order, the random effect of heifer within order, and the residual error. The compound symmetry covariance structure was selected on the basis of best fit according to Schwarz's Bayesian information criterion. No effect was observed at either test time of test number on response (weight pushed; $P$ $<0.39$, or latency to access the door; $P<0.97$ ), so data were averaged by heifer across multiple tests, within each treatment period and test time.

To assess the effect of treatment and time of day on response to the motivational test (weight pushed, weight pushed as a percentage of BW, total number of door pushes, and latency to push the door), data were analyzed using the MIXED procedure of SAS (SAS Institute, 2009) treating test time as a repeated measure. The model included the fixed effects of period, treatment, test time, treatment $\times$ test time interaction, order, the random effect of heifer within order, and the residual error. The compound symmetry covariance structure was selected on the basis of best fit according to Schwarz's Bayesian information criterion. For multiple comparisons between treatments and test times, the Tukey-Kramer method was used to adjust the probability differences between least squares means. To further assess presence of motivation to access the door, the number of times the door was pushed was tested for a difference from 0 using $t$-tests within the MIXED procedure of SAS (SAS Institute, 2009) for both treatments at both test times.

All values reported are least squares means. Normality of all data sets was verified before analysis using box plots and tests for normality (PROC UNIVARIATE; SAS Institute, 2009). Significance was declared as $P \leq$ 0.05 .
When on the LF treatment, heifers spent less time feeding (82.4 vs. $209.3 \mathrm{~min} / \mathrm{d} ; \mathrm{SE}=6.2 ; P<0.001)$ and ruminating (318.3 vs. $452.2 \mathrm{~min} / \mathrm{d} ; \mathrm{SE}=15.8 ; P$ $<0.001)$ than when they were on the CON treatment. Reduced feeding and ruminating time on the LF treatment likely resulted from both lower DMI (7.2 vs. 12.9 $\mathrm{kg} / \mathrm{d} ; \mathrm{SE}=0.6 ; P<0.001)$ and the lower percentage of fibrous feed in the ration (increased haylage) because cattle spend more time chewing and ruminating bulky feeds consisting mainly of long particles because this type of feed requires more mechanical breakdown to expose the surface to rumen microbes for digestion (Beauchemin et al., 2008). Differences in feeding time resulting from feeding strategy are similar to those reported previously: heifers limit-fed at $2.02 \%$ of $\mathrm{BW}$ spent less than $75 \mathrm{~min} / \mathrm{d}$ feeding compared with over $200 \mathrm{~min} / \mathrm{d}$ feeding when fed ad libitum (Kitts et al., 2011). In addition to effects on feeding time, feeding strategy affected rate of intake, with heifers fed CON having reduced rates of intake compared with heifers fed LF (0.06 vs. $0.09 \mathrm{~kg}$ of DM $/ \mathrm{min} ; \mathrm{SE}=0.004 ; P=$ $0.001)$. Greater rates of intake in restricted-fed animals are commonly reported (e.g., in poultry, Sandilands et al., 2006; and swine, Terlouw et al., 1991) and possibly arise due to increased feeding motivation resulting from discrepancies between desired and actual feed intake (Lawrence and Illius, 1989).

Further, heifers exposed to different feeding strategies distributed their feeding and rumination time over the day differently (Figure 1a, b). Diurnal patterns of average hourly feeding and ruminating time were subject to treatment $\times$ hour interactions $(P<0.001)$. Heifers on the LF treatment distributed the majority $(90 \%)$ of their time feeding within the first $3 \mathrm{~h}$ after feed delivery, with some LF heifers spending short periods of time feeding up to $6 \mathrm{~h}$ after delivery. When exposed to the CON treatment, heifers distributed their feeding time and, to a lesser extent, their rumination time across the day to a greater extent than when they were on the LF treatment. Similar diurnal patterns of limitfed compared with ad libitum-fed heifers were reported previously, with limit-fed heifers consuming their feed completely within $\sim 3 \mathrm{~h}$ of feed delivery (Kitts et al., 2011; Greter et al., 2012). In comparison, the diurnal feeding and ruminating patterns of heifers on the CON treatment are more reflective of natural feeding behavior, wherein cattle consume several small, short meals throughout the day and spend a similar period of time ruminating their feed (Hafez and Bouissou, 1975).

During the motivational tests, weight pushed (total and as a $\%$ of BW) and times the door was pushed were subject to treatment $\times$ time interactions as well as treatment and time effects: when heifers were on the 

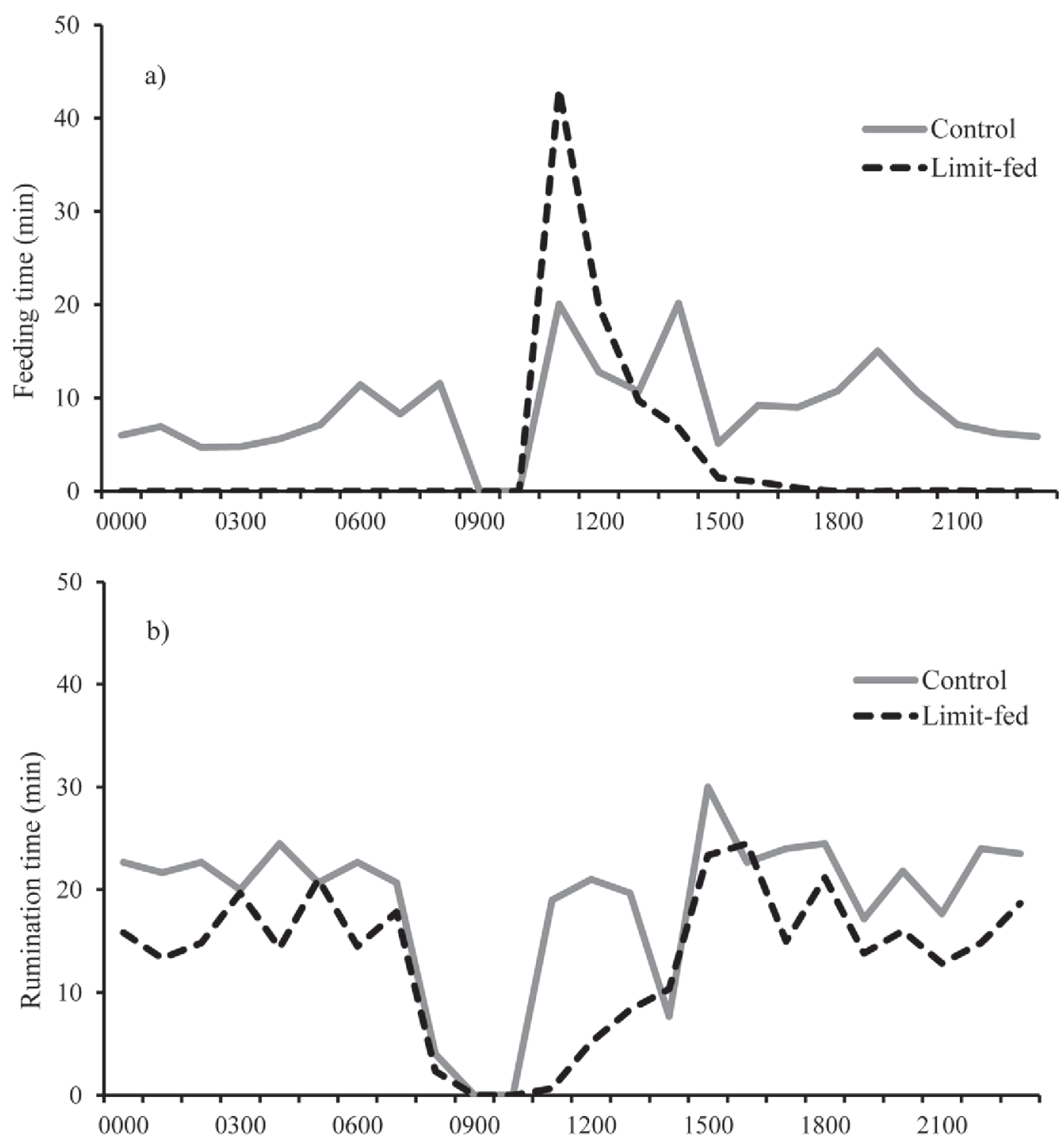

Time of day (h)

Figure 1. Diurnal (a) feeding time $(\mathrm{SE}=1.46)$ and $(\mathrm{b})$ rumination time $(\mathrm{SE}=3.33)$ of dairy heifers when limit-fed a low-forage TMR at $2.05 \% \mathrm{BW}$ or provided a high-forage TMR ad libitum (control). Data are averaged across $7 \mathrm{~d}$ (feeding time) or $3 \mathrm{~d}$ (rumination time) for 10 heifers on each treatment.

LF treatment, they pushed more weight, total and as a percentage of $\mathrm{BW}$ than when they were on the $\mathrm{CON}$ treatment (Table 2), and this differences was greater when the test occurred $21 \mathrm{~h}$ after feed delivery. Corresponding to differences in weight pushed, the number of times the door was accessed was greater when heifers were on the LF treatment, especially after the longer period of feed deprivation. In contrast, the number of times heifers accessed the door when on the CON treatment did not differ significantly from 0 , suggesting that they were minimally motivated to access straw when they had constant access to a TMR. When on the LF treatment, heifers had shorter latency to access the push door than when on the CON treatment, but latency was not affected by time of test. Similar to the present results, feed-restricted ewes have been found to work harder for food rewards and approach the feeding station faster than unrestricted controls (Verbeek et al., 2011) and access a push-door apparatus more often and more quickly than control (Jackson et al., 1999).

It is perhaps surprising that, when on the LF treatment, heifers were already motivated to access straw 
Table 2. Response to motivation test by dairy heifers provided a limit-fed, low-forage TMR at 2.05\% BW (LF) or a control, high-forage TMR $(\mathrm{CON})^{1}$

\begin{tabular}{|c|c|c|c|c|c|c|c|c|}
\hline \multirow[b]{2}{*}{ Item } & \multicolumn{2}{|c|}{$\mathrm{LF}$} & \multicolumn{2}{|c|}{$\mathrm{CON}$} & \multirow[b]{2}{*}{$\mathrm{SE}$} & \multicolumn{3}{|c|}{$P$-value } \\
\hline & $3 \mathrm{~h}$ & $21 \mathrm{~h}$ & $3 \mathrm{~h}$ & $21 \mathrm{~h}$ & & Treatment & Time & $\begin{array}{l}\text { Treatment } \\
\times \text { time }\end{array}$ \\
\hline Maximum weight pushed (kg) & $15.3^{\mathrm{b}}$ & $30.6^{\mathrm{a}}$ & $6.7^{\mathrm{c}}$ & $9.9^{\mathrm{bc}}$ & 2.65 & $<0.001$ & 0.002 & 0.02 \\
\hline Maximum weight pushed (\% of BW) & $4.5^{\mathrm{b}}$ & $9.3^{\mathrm{a}}$ & $1.9^{\mathrm{c}}$ & $2.8^{\mathrm{bc}}$ & 0.81 & $<0.001$ & 0.003 & 0.02 \\
\hline Times door was pushed (no./test) & $3.7^{\mathrm{b}}$ & $10.2^{\mathrm{a}}$ & $0.9^{\mathrm{c} *}$ & $1.9^{\mathrm{bc} *}$ & 1.09 & $<0.001$ & 0.002 & 0.01 \\
\hline Latency to push $(\mathrm{s})$ & $82.0^{\mathrm{b}}$ & $48.0^{\mathrm{b}}$ & $145.6^{\mathrm{a}}$ & $145.3^{\mathrm{a}}$ & 31.45 & 0.03 & 0.60 & 0.60 \\
\hline
\end{tabular}

${ }^{\mathrm{a}-\mathrm{c}}$ Means within a row with different superscripts differ $(P<0.05$; adjusted for multiple comparisons using the Tukey-Kramer procedure).

${ }^{1}$ Data are averaged across 3 tests/heifer/test time (3 or $21 \mathrm{~h}$ after feed delivery) in each treatment period.

*Values did not differ from $0(P>0.1)$.

$3 \mathrm{~h}$ after feed delivery, and worked harder at this time point than heifers fed CON. At this time of day, LF heifers had only recently finished consuming their daily feed allotment (Figure 1a) and, it could be assumed, had reached the maximum level of satiety likely to be experienced when fed according to this feeding strategy. The greater willingness of heifers to work to access straw immediately following intake of TMR when fed LF as opposed to CON is concerning because it suggests that they may not have been satiated even immediately following intake of their daily TMR. It is also possible that motivation to access additional feed at this time may have been influenced by the learned expectation that no additional feed would be available for the duration of the day (Collier and Johnson, 1990). In support of this effect of learning on feeding patterns, evidence shows that rate of intake remains greater at time of feed delivery for animals with previous experience being limit-fed (e.g., calves raised with restricted milk access; Miller-Cushon et al., 2013; and heifers previously exposed to limited allotments of concentrate; Greter et al., 2010).

When heifers were fed LF, they worked $\sim 2$ times as hard for a reward during the test occurring $21 \mathrm{~h}$ after feeding compared with the test occurring $3 \mathrm{~h}$ after feeding, pushing almost $10 \%$ of BW (Table 2). As the test at $21 \mathrm{~h}$ after feed delivery followed a period of feed deprivation for heifers on the LF treatment (approximately $19.5 \mathrm{~h}$ ), it is likely that feelings of hunger, frustration due to lack of foraging substrate, or both, were considerably higher at this time. Similar to the present results, Schütz et al. (2006) reported that lactating dairy cattle linearly increased the distance walked for a food reward, an indicator of feeding motivation, with duration of feed deprivation $(0,3,6$, or $9 \mathrm{~h}$ ). Motivation to access straw in the present study is likely also due to restricted feeding time in LF heifers (Figure 1a). Cattle have a behavioral need to forage that is partially independent of gut fill (Lindström and Redbo, 2000), suggesting that, although LF rations are formulated to meet energy demands to sustain growth, restricted foraging time likely reduces satiety.

It is also possible that motivation to access straw was influenced by within-day depressions in rumen $\mathrm{pH}$ in LF heifers, as consumption of straw would help to ameliorate low rumen $\mathrm{pH}$ by increasing salivary secretion (Beauchemin et al., 2008). Decline in rumen $\mathrm{pH}$ following feeding is proportional to the size of the meal (Krause and Oetzel, 2006), and it is therefore likely that limit feeding results in prolonged bouts of low rumen pH. Dairy cattle experiencing bouts of low rumen $\mathrm{pH}$ have been shown to select in favor of longer forage particles, which may improve rumen environment (Keunen et al., 2002; DeVries et al., 2008), suggesting that heifers fed LF may have been similarly motivated to consume straw.

In conclusion, limit-fed dairy heifers had reduced feeding time, increased rate of intake, and restricted natural diurnal feeding patterns compared with heifers fed ad libitum. Heifers worked harder to access oat straw, by pushing a weighted door, when limit-fed compared with when fed ad libitum, especially $21 \mathrm{~h}$ after feed delivery compared with $3 \mathrm{~h}$ after feed delivery. These results suggest that limit-fed heifers are motivated to access a low-nutritive feedstuff, possibly due to lack of gut fill or an unsatisfied behavioral need to forage. Thus, it is recommended that a low-nutritive feedstuff be provided alongside a limit-fed TMR to allow heifers to express normal feeding behavior and diurnal feeding patterns.

\section{ACKNOWLEDGMENTS}

We thank the staff and students at the University of Guelph, Kemptville Campus Dairy Education and Research Centre (Kemptville, Ontario, Canada), particularly Megan Bruce, Morgan Overvest, Maarten Prinsen, and John Wynands. Angela Greter was supported by a Natural Sciences and Engineering Research Council of Canada (Ottawa, Ontario, Canada) Alexander Graham Bell Canadian Graduate Scholarship. This project was 
funded through support from the Campbell Centre for the Study of Animal Welfare (University of Guelph, Guelph, Ontario, Canada), the Ontario Ministry of Agriculture, Food and Rural Affairs (Guelph, Ontario, Canada), the Canadian Foundation for Innovation (Ottawa, Ontario, Canada), and the Ontario Research Fund (Ministry of Research and Innovation, Toronto, Ontario, Canada).

\section{REFERENCES}

AOAC International. 2000. Official Methods of Analysis. Vol. I. 17th ed. AOAC International, Arlington, VA.

Beauchemin, K. A., L. Eriksen, P. Nørgaard, and L. M. Rode. 2008. Salivary secretion during meals in lactating dairy cattle. J. Dairy Sci. 91:2077-2081.

Canadian Council on Animal Care. 2009. Guidelines on: The care and use of farm animals in research, teaching and testing. Canadian Council on Animal Care, Ottawa, ON, Canada.

Collier, G., and D. F. Johnson. 1990. The time window of feeding. Physiol. Behav. 48:771-777.

D'Eath, R. B., B. J. Tolkamp, I. Kyriazakis, and A. B. Lawrence. 2009. 'Freedom from hunger' and preventing obesity: The animal welfare implications of reducing food quantity or quality. Anim. Behav. 77:275-288.

DeVries, T. J., F. Dohme, and K. A. Beauchemin. 2008. Repeated ruminal acidosis challenges in lactating dairy cows at high and low risk for developing acidosis: Feed sorting. J. Dairy Sci. 91:39583967.

Greter, A. M., T. J. DeVries, and M. A. G. von Keyserlingk. 2008. Nutrient intake and feeding behavior of growing dairy heifers: Effects of dietary dilution. J. Dairy Sci. 91:2786-2795.

Greter, A. M., B. L. Kitts, and T. J. DeVries. 2011. Limit feeding dairy heifers: Effect of feed bunk space and provision of a low-nutritive feedstuff. J. Dairy Sci. 94:3124-3129.

Greter, A. M., K. E. Leslie, G. J. Mason, B. W. McBride, and T. J. DeVries. 2010. Feed delivery method affects the learning of feeding and competitive behavior in dairy heifers. J. Dairy Sci. 93:37303737.

Greter, A. M., M. A. G. von Keyserlingk, and T. J. DeVries. 2012. Ration composition affects short-term diurnal feeding patterns of dairy heifers. Appl. Anim. Behav. Sci. 140:16-24.

Hafez, E. S. E., and M. F. Bouissou. 1975. The behaviour of cattle. Pages 203-245 in The Behaviour of Domestic Animals. E. S. E. Hafez, ed. Bailliere Tindall, London, UK.

Hoffman, P. C., C. R. Simson, and M. Wattiaux. 2007. Limit feeding of gravid Holstein heifers: Effect on growth, manure nutrient excretion, and subsequent early lactation performance. J. Dairy Sci. 90:946-954.

Jackson, R. E., N. K. Waran, and N. K. Cockram. 1999. Methods for measuring feeding motivation in sheep. Anim. Welf. 8:53-63.

Keunen, J. E., J. C. Plaizier, L. Kyriazakis, T. F. Duffield, T. M. Widowski, M. I. Lindinger, and B. W. McBride. 2002. Effects of a subacute ruminal acidosis model on the diet selection of dairy cows. J. Dairy Sci. 85:3304-3313.
Kilgour, R. J. 2012. In pursuit of "normal": A review of the behaviour of cattle at pasture. Appl. Anim. Behav. Sci. 138:1-11.

Kirkden, R. D., and E. A. Pajor. 2006. Using preference, motivation and aversion tests to ask scientific questions about animals' feelings. Appl. Anim. Behav. Sci. 100:29-47.

Kitts, B. L., I. J. H. Duncan, B. W. McBride, and T. J. DeVries. 2011. Effect of the provision of a low-nutritive feedstuff on the behavior of dairy heifers fed a high-concentrate ration in a limited amount. J. Dairy Sci. 94:940-950.

Krause, M. K., and G. R. Oetzel. 2006. Understanding and preventing subacute ruminal acidosis in dairy herds: A review. Anim. Feed Sci. Technol. 126:215-236.

Lascano, G. J., G. I. Zanton, F. X. Suarez-Mena, and A. J. Heinrichs. 2009. Effect of limit feeding high- and low-concentrate diets with Saccharomyces cerevisiae on digestibility and on dairy heifer growth and first-lactation performance. J. Dairy Sci. 92:51005110 .

Lawrence, A. B., and A. W. Illius. 1989. Methodology for measuring hunger and food needs using operant conditioning in the pig. Appl. Anim. Behav. Sci. 24:273-285.

Lindström, T., and I. Redbo. 2000. Effect of feeding duration and rumen fill on behaviour in dairy cows. Appl. Anim. Behav. Sci 70:83-97.

Miller-Cushon, E. K., R. Bergeron, K. E. Leslie, and T. J. DeVries. 2013. Effect of milk feeding level on development of feeding behavior in dairy calves. J. Dairy Sci. 96:551-564.

Morris, T. R. 1999. Experimental Design and Analysis in Animal Sciences. CABI Publishing, New York, NY.

NRC. 2001. Nutrient Requirements for Dairy Cattle. Natl. Acad. Sci., Washington, DC

Olsson, I. A. S., and L. J. Keeling. 2002. The push-door for measuring motivation in hens: Laying hens are motivated to perch at night. Anim. Welf. 11:11-19.

Redbo, I., M. Emanuelson, K. Lundberg, and N. Oredsson. 1996. Feeding level and oral stereotypies in dairy cows. Anim. Sci. 62:199 206.

Sandilands, V., B. J. Tolkamp, C. J. Savory, and I. Kyriazakis. 2006. Behaviour and welfare of broiler breeders fed qualitatively restricted diets during rearing: Are there viable alternatives to quantitative restriction? Appl. Anim. Behav. Sci. 96:53-67.

SAS Institute Inc. 2009. User's Guide: Statistics. Version 9.1.3 ed. SAS Institute Inc., Cary, NC.

Schütz, K., D. Davison, and L. Matthews. 2006. Do different levels of moderate feed deprivation in dairy cows affect feeding motivation? Appl. Anim. Behav. Sci. 101:253-263.

Terlouw, E. M. C., A. B. Lawrence, and A. W. Illius. 1991. Influences of feeding level and physical restriction on development of stereotypies in sows. Anim. Behav. 42:981-991.

Van Soest, P. J., J. B. Robertson, and B. A. Lewis. 1991. Methods for dietary fiber, neutral detergent fiber and nonstarch polysaccharide in relation to animal nutrition. J. Dairy Sci. 74:3583-3597.

Verbeek, E., J. R. Waas, L. McLeay, and L. R. Matthews. 2011. Measurement of feeding motivation in sheep and the effects of food restriction. Appl. Anim. Behav. Sci. 132:121-130.

Zanton, G., and J. Heinrichs. 2008. Precision feeding dairy heifers: Strategies and recommendations. Pennsylvania State Univ. DAS08-130. Pennsylvania State Univ., University Park. 